\title{
On the Viable Linkages between Extroversion/Introversion and Academic Iranian EFL Learners' Writing Proficiency
}

\author{
Parviz Alavinia $^{1} \&$ Adel Hassanlou ${ }^{2}$ \\ ${ }^{1}$ Department of English Language and Literature, Faculty of Humanities and Letters, Urmia University, Iran \\ ${ }^{2}$ Department of English Language and Literature, Urmia Branch, Islamic Azad University, Iran \\ Correspondence: Parviz Alavinia, Department of English Language and Literature, Faculty of Humanities and \\ Letters, Urmia University, Valfajr 2 Blvd., Urmia, West Azerbaijan, Iran. Tel: 0098-0441-3362012. E-mail: \\ pevinia2006@yahoo.com
}

Received: November 18, 2013 Accepted: December 19, 2013 Online Published: February 12, 2014

doi:10.5539/elt.v7n3p167 URL: http://dx.doi.org/10.5539/elt.v7n3p167

\begin{abstract}
The current study was aimed at investigating the relationship between academic Iranian EFL learners' extroversion/introversion and their writing performance. The participants of the study were some $52 \mathrm{BA}$ learners majoring in English language literature in Urmia and Tabriz state universities. The chosen sample comprised of both males and females and as convenience sampling was utilized, all the participants took part in the study on a voluntary basis. The major instrument used in the study was the online version of Eysenck's personality questionnaire, which was exerted as the means of determining the learners' extroversion/introversion. Furthermore, to gauge the learners' writing performance, they were asked to write three types of essays (argumentative, narrative and descriptive). Through the final analysis of data, it was revealed that no significant correlation held between the participants' personality types and their writing performance in terms of all three modes referred to. A statistically significant difference was, however, observed between the writing performance of male and female students.
\end{abstract}

Keywords: extraversion, Eysenck's peronality questionaire, introversion, writing proficiency

\section{Introduction}

The interface between pedagogy and psychology, which, in turn, brought about the advent of hybrid disciplines such as educational psychology and psycholinguistics, might be thought of as a milestone in the developmental progression of EFL/SLA. Among the manifold influential breakthroughs in the long-lasting history of language teaching, one can refer to the realization of individual differences in learners as a highly determining factor in producing desirable learning outcomes. The increasing heed paid to the learners' diverse personality traits, as well as their unique needs and preferences, has revolutionized the manner in which learners are being treated in modern educational settings.

Among the myriad personality traits and individual differences recognized and explored in relation to learning and pedagogy, lie the fundamental concepts of extroversion and introversion. The contention that introverts and extroverts have different priorities in selecting their favorite activity to learn the language skills is now endorsed by educationalists. While extroverts are inclined toward having more social interactions with the others, introverts have an appeal toward concentration and self-sufficiency. As Arnold and Brown (1999, p. 11) put it, "extroversion has to do with the need for receiving ego enhancement, self-esteem and a sense of wholeness from other people, while introversion refers to the degree that individuals derive this sense from within themselves."

As a highly challenging task, writing has turned to a notorious skill among most language learners, mastery over which is thought to demand expending a considerable amount of time and energy. To adopt Celce-Murcia's (2001, p. 205) words, "The ability to express one's ideas in writing in a second or foreign language and to do so with reasonable coherence and accuracy is a major achievement." That gaining the full command of writing in a foreign language requires ongoing systematic practice is no question, yet how to overcome the insurmountable aura ascribed to writing is a highly debatable issue which is in need of more thoughtful deliberation.

Part of the intractability and insuperability of writing is found to emanate from the problem with how to motivate learners in the first place. In this regard, the responsibility of the teachers in attempting to bring their learners 
into closer terms with the writing task seems to be of utmost significance. As Kroll (1990, p. 1) states, "becoming a writer is a complex and ongoing process, and becoming a writing teacher is no less complex." Once set on the task with an ample amount of avidity, learners are liable to find writing less of a gruesome nature, and provided that the topic on which they write is captivating enough to keep them motivated up to the end, their overall outlook toward writing is likely to go through considerable change and betterment.

One way to counteract the so-called repugnance commonly associated with writing is thought to be materialized via a reconsideration of the feasible role of individual differences in bringing learners to closer terms with writing. Thus, in an attempt to reappraise the would-be bonds between such individual personality traits and the learners' writing propensities and proclivities, the researchers in the current study strived to probe the potential relationship between the learners' extroversion/introversion and their writing performance on three distinct modes of writing, i.e. argumentative, narrative and descriptive. To be able to come up with satisfactory answers to the principal study postulations, the following research questions were formulated:

$\mathrm{RQ}_{1}$ : Is there any statistically significant relationship between the personality type (introversion vs. extroversion) of Iranian university EFL students and their writing performance?

$\mathrm{RQ}_{1 \mathrm{a}}$ : Is there any statistically significant relationship between the personality type of Iranian university EFL students and their argumentative writing performance?

$\mathrm{RQ}_{1 \mathrm{~b}}$ : Is there any statistically significant relationship between the personality type of Iranian university EFL students and their narrative writing performance?

$\mathrm{RQ}_{1 \mathrm{c}}$ : Is there any statistically significant relationship between the personality type of Iranian university EFL students and their descriptive writing performance?

$\mathrm{RQ}_{2}$ : Is there any statistically significant difference between the writing performances of advanced EFL learners across the same personality type from a gender perspective?

\section{Literature Review}

\subsection{Empirical Research on Introversion/Extroversion}

Though different delineations have been offered for the terms extroversion and introversion, Eysenck and Chan's (1982) characterization of this dichotomy appears to be more illuminating:

Extraverts are sociable, like parties, have many friends and need excitement; they seek sensation and take a lot of risks, like practical jokes and are lively and don't like to be passive. Conversely introverts are quiet, prefer reading to meeting people, have few but close friends and usually avoid excitement (cited in Ellis, 2008, p. 586).

Though extroversion and introversion are thought to be quite straightforward notions, the major problem might be that these terms are surrounded by fatal misconceptions, particularly in classroom learning context "where teachers admire the talkative, outgoing student who participates freely in class discussions. On the other hand, introverts are sometimes thought of as not being as bright as extroverts" (Brown, 1994, p. 145). In this regard, Arnold and Brown (1999, p. 11) argue that "Extroverts are often stereotyped as being outgoing and talkative and, therefore, better language learners, since they are more likely to participate openly in the classroom and seek out opportunities to practise." Introverts, on the other hand, as they continue to aver, "might be considered less apt language learners, since they seem to be too reserved, too self-restrained." Furthermore, as Lightbown and Spada (2006, p. 53) contend, "many teachers are convinced that extroverted learners who interact without inhibition in the second language and seek opportunities to practise language skills will be the most successful learners."

Despite these prevalent misconceptions about the direct relationship between extroversion and success in language learning, there are researchers who have come up with different results. Indeed, the outcomes of studies dealing with these debatable personality factors are quite controversial at times. In line with Lightbown and Spada (2006),

Although some studies have found that success in language learning is correlated with learners' scores on questionnaires measuring characteristics associated with extroversion such as assertiveness and adventurousness, others have found that many successful language learners do not get high scores on measures of extroversion (pp. 60-61).

Indeed, research (e.g. Busch, 1982; Naiman, Frohlich, Stern, \& Todesco, 1978, as cited in Brown, 1994) has sometimes put extroverts at a disadvantageous position with regard to success in language learning. In Busch's investigation, for instance, introverts were found to outperform their extrovert counterparts in terms of oral proficiency and pronunciation. Thus, faced with this amalgam of contradictory upshots, some researchers like Skehan (1989) have been drawn to conclude that based on the scanty and murky results thus far obtained, no 
firm conclusions are to be hastily made and further research is required to confirm the claims made in favor of either group of individuals. Also, as Arnold and Brown (1999, p. 11) maintain, the current state of research does not permit us to draw firm conclusions as to whether either extroversion or introversion is directly related to success in language learning. However, what is clear is that certain types of classroom activities are more appropriate for one or the other.

Though studies on extroversion and introversion abound in the literature, most research on the issue has been of miscellaneous nature. For instance, one line of research has viewed these personality traits in relation to other variables, including learning strategies (e.g. Fazeli, 2012; Wakamoto, 2000), risk-taking (e.g. Zafar \& Meenakshi, 2012), socioeconomic factors (e.g. Dhody, 2012) and emotions (e.g. Verduyn \& Brans, 2012). Other studies have opted for analyzing the would-be correlation between extroversion/introversion and language learning skills (e.g. Alavinia \& Sameei, 2012; Widyastuti, 2012) and components (e.g. Busch, 1982, as cited in Brown, 1994). Faced with this variation apropos studies done in this domain, in what follows the researchers initially deal with the investigations relating these personality factors with other variables. Then, they will go over some skills-related research and end up this section with some research addressing writing proficiency. In so doing, an attempt is made to go over only some of the most recent probes carried out in this entrancing sphere of psycholinguistic studies.

In an early study on learners' extroversion, Wakamoto (2000) embarked on an investigation of the correlation between language learning strategies and Extraversion in a sample of 254 subjects of junior college majoring in English. He found that extroverts tend to have "functional practice strategies" and "social affective strategies". Functional practice strategy is the strategy in which learners tend to focus on the meaning rather than form. Wakamoto says that this is crucial for language learning, particularly in communication either via speaking or writing. The social affective strategy is not so different. By implementing this strategy, extrovert people like to get involved in asking questions, through which they get more opportunities for communication. Therefore, by opting for these two strategies, extroverts are thought to enjoy a more privileged position compared to introverts.

In another study with a similar focus, Fazeli (2012) delved into the would-be relationship between learners' extroversion and their utilization of language learning strategies. Administering four questionnaires - including Strategy Inventory for Language Learning (SILL) and NEO-Five Factors Inventory (NEO-FFI) - to 213 Iranian female academic learners, the researcher concluded that a significant amount of correlation prevails between the learners' extroversion and their use of language learning strategies.

In their query concerning the possible bonds between extroversion-introversion and risk-taking ability in individuals, Zafar and Meenakshi (2012) go through what literature offers regarding the characteristics of learners possessing each personality trait and conclude that while extroverts enjoy an advantageous position with regard to winning more opportunities for putting language into use, introversion is not thought to put learners in an inferior position, as this latter trait empowers learners to act better in terms of certain other skills including writing and reading. Yet, as risk-taking, which is a positive strategy in learning, is mostly associated with extroversion, extroverts in this study are regarded as more efficient learners in that they are said to be more actively involved in classroom process.

In another interesting attempt aimed at probing the effect of socio-economic factors and social status on the degree of extroversion/introversion in learners, Dhody (2012) chose a sample of 100 female learners (fifty high and fifty low in terms of socio-economic status), and through administering a questionnaire found that socio-economic conditions of learners don't significantly affect their personality traits in terms of the degree of extroversion and introversion.

In another correlational analysis dealing with the potential linkages between extroversion and neuroticism, on the one hand, and duration of positive and negative emotions, on the other, Verduyn and Brans (2012) asked a group of participants to report the degree, frequency and duration of positive and negative emotions influencing them each day with this process going on for an entire week. This research culminated in reporting a positive correlation between extroversion and positive emotions with respect to the three factors in question, i.e. duration, frequency and intensity of emotions. Neuroticism, however, correlated with negative emotions in terms of duration and frequency factors.

As an instance of skills-related research, Alavinia and Sameei (2012) strived to study the viable relationship between introversion/extroversion and the listening ability of intermediate Iranian EFL learners. In so doing, they also investigated the possible role of learners' gender, age, and grades of study in relation to this correlation. To conduct the research, 120 Intermediate institute learners were selected and asked to fill Eysenck's Personality Questionnaire. Successive to running the statistical analysis through Pearson correlation and two-way analysis of 
variance, it was revealed that a significant amount of relationship held between the learners' listening ability and their personality types, i.e. extroversion and introversion (introvert individuals were found to be at an advantageous position in this regard). Furthermore, while the participants' age and grades of study were found to significantly correlate with their personality type and listening ability, no such significant relationship was reported for gender variable.

A more relevant investigation to refer to in terms of variables explored is the study carried out by Widyastuti (2012), in which some 346 tenth-graders were recruited for the research out of which only 30 were chosen for the main study. Intending to gauge the possible correlation between learners' extroversion and their writing ability as well as vocabulary knowledge, the researcher administered a questionnaire and two tests to these learners and through running Pearson correlation analysis on the obtained data found that extroversion correlates with not only learners' writing ability, but also with their vocabulary power. A significant positive correlation was also reported between learners' vocabulary strength and their writing ability.

Learners' writing proficiency has been viewed in the literature in the light of many other factors including efficient use of learning strategies (e.g. Jones, 1982, as cited in Krapels, 1990) and the frequency of using cohesive devices (e.g. Alarcon \& Morales, 2011; Dastjerdi \& Samian, 2011). In this regard, Jones (ibid.) embarked on a probe with two L2 writers, a poor one and a good one, and through the process of composing aloud found that "writing strategies affected writers' rhetorical structures." As Jones contended, "the poor writer was bound to the text at the expense of ideas, whereas the good writer allowed her ideas to generate the text" (Jones, 1982, as cited in Krapels, 1990, p. 40).

Furthermore, in their probe into the use of cohesive devices in argumentative essays, Dastjerdi and Hayati Samian (2011) experimented with a sample of 40 Iranian graduates majoring in non-English disciplines. Adopting Halliday and Hassan's (1976) framework, they also examined learners' writing quality in terms of the number of cohesive devices utilized in the process of writing. The results of this investigation revealed the familiarity of students with cohesive devices and the satisfactory use of these devices in their written work. While lexical devices were characterized by the highest percentage of use among other cohesive devices, reference devices and conjunction devices ranked second and third in terms of frequency of use in learners' written production. Nonetheless, no significant relationship was found to exist between the use of cohesive devices and learners' writing quality and efficiency.

Likewise, Alarcon and Morales (2011) embarked on an analysis of the role of cohesive devices in students' written production and, in so doing, employed Halliday and Hassan's model as the major framework for the categorization of cohesive markers. Though initial sample utilized was considerably bigger, the number of eligible essays on which the final analysis was performed reduced to only 64. Subsequent to data analysis, it was revealed that reference markers had been used more frequently than the other types of cohesive devices in participants' essays. Though, based on qualitative data, some cohesive devices were reported to have helped learners in formulating better argumentations, the findings through quantitative analysis didn't point to any significant correlation between the use of cohesive devices and the quality of writing.

After all, the brief overview provided in this section concerning the literature on the efficacy of learners' writing might draw us to conclude that though writing proficiency and how to achieve it has always been a serious preoccupation for most SLA researchers, very few investigators have delved into the go-togetherness between writing proficiency and personality traits such as extroversion/introversion. Thus, in an attempt to address this rarely-touched area of scrutiny, the researchers in the current study are after probing the possible correlation between these personality traits and learners' writing performance on argumentative, narrative and descriptive essays.

\section{Mehtod}

\subsection{Participants}

A total of 52 male and female students of English Language and Literature participated in the current research. The study partakers were bachelor students from Urmia and Tabriz state universities, and in terms of age range, the majority of learners were between 22 and 23. As partial acquaintance with essay writing essentials was deemed elemental in the selection of sample, all the participants were required to have passed advanced writing as well as essay writing courses.

\subsection{Instruments}

The principal means of data collection in the current study was the online version of Eysenck's personality questionnaire which was mainly utilized for measuring the individuals' extroversion/introversion. The 
questionnaire encompassed one hundred items with Yes/No responses. Each page of the questionnaire contained 10 questions, after the completion of which the learners were required to save the page and go on with the rest, until they reached the end of the questionnaire. After the entire questionnaire was filled out in this computer-assisted manner, the results for each learner were automatically calculated and reported by the computer software, without any need for manual operations. At this stage, the learners were asked to save the total result gained in a separate file under their names on the computer desktop. The whole process of data collection in this manner took around 20 minutes for each student. The other instrument exerted in the study was a set of IELTS writing topics in three separate modes, i.e. argumentative, narrative and descriptive.

\subsection{Data Collection Procedure}

Data relevant to learners' personality traits, i.e. extroversion/introversion were gathered in the presence of the course instructors who were already asked to allocate part of the class time to online data collection. To do this, the learners were demanded to go to internet site, and due to insufficiency of PCs some had to wait until their classmates were through. All the participants were primarily briefed on the purposes for which the test was being administered; they were, further, reassured that the results of the test would be kept confidential. Moreover, as the results of the test were automatically calculated and reported by the software, they could get ready access to their personality type and there was, accordingly, no need to wait for the outcomes to be announced later. This novel manner of test-taking was thought to provide them with some sort of motive for going on with the process.

Subsequent to this stage, the learners were asked to write three essays in argumentative, narrative and descriptive modes. To cater for inter-rater reliability, two experts were asked to score each essay, the mean score of which was later considered as the final score obtained by each participant. In an attempt to reduce the degree of subjectivity in scoring, TOEFL Guidelines on how to score writing tasks were employed. Thus, the principal criteria set for the correction procedure based on TOEFL grading system encompassed grammatical accuracy, spelling, punctuation, cohesion and coherence, appropriate word choice and making sense. The raters were also asked to rate the essays on the scale of 100 . As an instance, to calculate the first participants' score on the argumentative essay, two copies of the original written essay were made by the researchers, which were then passed to the two raters. As the raters' scores given to this participant's essay were 65 and 70 , the mean score for this individual's grade amounted to 67.5 , which was later rounded to 68 . The same process was pursued for narrative and descriptive essays and for the rest of the participants, as well. Furthermore, since the learners had been required to write their names on the essays, the researchers could specify their gender. In Table 1, a sample of the data filed for one of the participants in the study has been illustrated as an example:

Table 1. Sample data collected and filed for one of the study participants

\begin{tabular}{llllll}
\hline ID & Personality type & Gender & $\begin{array}{l}\text { Argumentative } \\
\text { essay score }\end{array}$ & $\begin{array}{l}\text { Narrative } \\
\text { essay score }\end{array}$ & $\begin{array}{l}\text { Descriptive } \\
\text { essay score }\end{array}$ \\
\hline 1 & Introvert & Male & 88 & 76 & 90 \\
\hline
\end{tabular}

\subsection{Data Analysis}

To analyze the first research question and its sub-questions, seeking to find the would-be relationship between the personality type of Iranian university EFL students and their writing performance in terms of the three modes of argumentative, narrative and descriptive essays, Pearson product moment correlation was run. Yet, as to the second research question which was after gauging the potential role of gender in the writing performances of advanced EFL learners across the same personality type, two-way analysis of variance was employed.

\section{Results and Discussion}

\subsection{Investigating the First Research Question}

$\mathrm{RQ}_{1}$ : Is there any statistically significant relationship between the personality type of Iranian university EFL students and their writing performance?

As the first research question of the study analyzes a three-fold issue, to provide for a more systematic discussion of the findings relevant to this question, the upshots gained through the analysis of data are presented under three separate headings, entitled Personality Type and Argumentative Writing, Personality Type and Narrative Writing, and Personality Type and Descriptive Writing. 


\subsubsection{Personality Type and Argumentative Writing}

$\mathrm{RQ}_{\mathrm{la}}$ : Is there any statistically significant relationship between the personality type of Iranian university EFL students and their argumentative writing performance?

As Table 2 illustrates, the mean score for argumentative writing among 52 students was 73.13 and the standard deviation equaled 8.83 .

Table 2. Descriptive statistics for personality type and argumentative essay

\begin{tabular}{llll}
\hline & Mean & Std. Deviation & $\mathrm{N}$ \\
\hline Personality & 1.50 & .505 & 52 \\
Argumentative & 73.13 & 8.83 & 52 \\
\hline
\end{tabular}

Additionally, the mean score of males' argumentative writing equaled 73.50, whereas the one for females was 73.14 (see Table 3). Therefore, a very slight difference was encountered between the mean scores of males and females in the argumentative writing.

Table 3. The mean scores for male and female participants on argumentative essay

\begin{tabular}{lll}
\hline Argumentative & Males' Mean Score & Females' Mean Score \\
\cline { 2 - 3 } Writing & 73.50 & 73.14 \\
\hline
\end{tabular}

Pearson Correlation results (Table 4) pointed to non-existence of a statistically significant correlation between the learners' personality type and their argumentative writing performance $(r=-.03 ; p=.817>.05)$. Thus, the first null hypothesis was confirmed.

Table 4. Pearson correlation test for personality and argumentative writing

\begin{tabular}{llll}
\hline & & Personality & Argumentative \\
\hline Personality & Pearson Correlation & 1 & -.033 \\
& Sig. (2-tailed) & & .817 \\
& $\mathrm{~N}$ & 52 & 52 \\
\hline
\end{tabular}

\subsubsection{Personality Type and Narrative Writing}

$\mathrm{RQ}_{1 \mathrm{~b}}$ : Is there any statistically significant relationship between the personality type of Iranian university EFL students and their narrative writing performance?

As is seen in Table 5, the mean score for narrative writing among 52 students was 73.53 and the standard deviation equaled 10.50 .

Table 5. Descriptive statistics for personality type and narrative essay

\begin{tabular}{llll}
\hline & Mean & Std. Deviation & $\mathrm{N}$ \\
\hline Personality & 1.50 & .505 & 52 \\
Narrative & 73.53 & 10.50 & 52 \\
\hline
\end{tabular}

Moreover, the mean score of narrative writing for males was 74.88 and the one for females equaled 69.41 . Accordingly, the difference between the two sets of mean scores for males and females was again very infinitesimal (see Table 6).

Table 6. The mean scores for male and female participants on narrative essay

\begin{tabular}{lll}
\hline Narrative & Males' Mean Score & Females' Mean Score \\
\cline { 2 - 3 } Writing & 74.88 & 69.41 \\
\hline
\end{tabular}


Finally, in line with Pearson correlation result (Table 7) no statistically significant correlation was reported to hold between the participants' personality type and their narrative writing performance $(r=-.10 ; p=.44>.05)$, and hence the second null hypothesis was not prone to rejection.

Table 7. Pearson correlation test for personality and narrative writing

\begin{tabular}{llll}
\hline & & Personality & Narrative \\
\hline Personality & Pearson Correlation & 1 & -.107 \\
& Sig. (2-tailed) & & .449 \\
& $\mathrm{~N}$ & 52 & 52 \\
\hline
\end{tabular}

\subsubsection{Personality Type and Descriptive Writing}

$\mathrm{RQ}_{1 \mathrm{c}}$ : Is there any statistically significant relationship between the personality type of Iranian university EFL students and their descriptive writing performance?

As is shown in Table 8, the mean score for descriptive writing was found to be 72.50 and the standard deviation equaled 9.51 .

Table 8. Descriptive statistics for personality type and descriptive essay

\begin{tabular}{llll}
\hline & Mean & Std. Deviation & $\mathrm{N}$ \\
\hline Personality & 1.50 & .505 & 52 \\
Descriptive & 72.50 & 9.51 & 52 \\
\hline
\end{tabular}

Additionally, based on what is reported in Table 9, the mean score of descriptive writing for males was 74.00 and the one for females equaled 69.55. Hence, similar to the previous cases referred to for the other two modes of writing, once more a very slight amount of difference is witnessed between the mean scores of male and female learners on descriptive mode.

Table 9. The mean scores for male and female participants on descriptive essay

\begin{tabular}{lll}
\hline Descriptive & Males' Mean Score & Females' Mean Score \\
\cline { 2 - 3 } Writing & 74.00 & 69.55 \\
\hline
\end{tabular}

Finally, through running Pearson correlation analysis (Table 10) it was revealed that no statistically significant correlation is at work between the partakers' personality type and their descriptive writing performance $(r=.15$; $p=.28>.05)$. Accordingly, the third null hypothesis was also confirmed.

Table 10. Pearson correlation test for personality and descriptive writing

\begin{tabular}{llll}
\hline & & Personality & Descriptive \\
\hline Personality & Pearson Correlation & 1 & .151 \\
& Sig. (2-tailed) & & .285 \\
& $\mathrm{~N}$ & 52 & 52 \\
\hline
\end{tabular}

\subsection{Investigating the Second Research Question}

$\mathrm{RQ}_{2}$ : Is there any statistically significant difference between the writing performances of advanced EFL learners across the same personality type from a gender perspective?

To find out the potential role of gender, a two-way ANOVA was run which revealed a statistically significant difference $(p=.047)$ between the learners' writing performance in terms of gender (see Table 11). Therefore, it can be stated that there is a statistically significant difference between gender and learners' writing performance, with males outperforming females in terms of writing performance across different personality types. 
Table 11. Two-way ANOVA result for the effect of gender on writing performance

\begin{tabular}{lllllll}
\hline Source & $\begin{array}{l}\text { Type III Sum of } \\
\text { Squares }\end{array}$ & Df & Mean Square & F & Sig. & $\begin{array}{l}\text { Partial Eta } \\
\text { Squared }\end{array}$ \\
\hline Corrected model & $1169.448^{\mathrm{a}}$ & 3 & 389.816 & 1.437 & .244 & .082 \\
Intercept & 1744725.865 & 1 & 1744725.865 & 6433.160 & .000 & .993 \\
Gender & 19.976 & 1 & 19.976 & .074 & .787 & .002 \\
Personality & 148.178 & 1 & 148.178 & .546 & .463 & .011 \\
Gender * personality & 1129.115 & 1 & 1129.115 & 4.163 & .047 & .080 \\
Error & 13017.995 & 48 & 271.208 & & & \\
Total & 2512103.000 & 52 & & & & \\
Corrected total & 14187.442 & 51 & & & & \\
\hline
\end{tabular}

To summarize the findings, it must be stated that the analysis of results revealed no statistically significant relationship between learners' personality types and their writing performance. Nonetheless, gender was realized as an important factor in determining writing efficiency of participants and a significant difference was found between the writing performance of males and females across different personality types.

The obtained results in the current study run contrary to the claims by Zafar and Meenakshi (2012) who underscore the differences between extroverts and introverts, and hold that introverts do better than their extrovert counterparts on writing and reading skills. The results gained are also in sharp contrast with the findings of Widyastuti's (2012) research, in which learners' extroversion was found to positively correlate with their writing ability. To justify the reason behind these contradictory results, it might suffice to refer to differences in terms of writing tasks administered to learners, among other potential contextual reasons. While the two studies cited have regarded learners' writing proficiency in its totality, the current research has analyzed participants' writing power along three separate modes of argumentative, narrative and descriptive essays.

Now why researchers' initial postulations regarding the potential differences between learners' writing quality in the light of their extroversion/introversion weren't confirmed in the current scrutiny might be worth giving thoughtful deliberation. Lack of significant results in this regard, as expected by the researchers, might be ascribed to a number of factors. First, self-report measures like the one used in the current study are notorious for providing the researchers with dodgy results, in that participants presented with such instruments tend to reveal what they conceive of as reality not the reality itself. Second, supposing that the questionnaire results have provided the researchers with the exact characteristics of learners in terms of extroversion/introversion, again such results cannot be taken for granted, as individuals tend to appear as either extroverts or introverts under different circumstances and these traits are not to be thought of as permanent, unchangeable attributes. Finally, other factors such as anxiety while doing the writing tasks within the set time limits are liable to have tampered with the results.

\section{Concluding Remarks}

This study attempted to investigate the relationship between learners' personality type (extrovert and introversion) and their writing performance along three different modes of argumentative, narrative and descriptive writing. Though the researchers postulated that differences are likely to exist between extroverts and introverts in terms of performance on different writing modes, the final analysis of data indicated that there is no statistically significant difference between learners' writing performance and their personality type and this finding held true for all three modes in question. Nevertheless, participants' gender was found to be a determining factor in relation to their writing performance.

The findings of the current study, though running contrary to the researchers' primary speculations, might, at the very least, help sensitize educationalists - including teachers, syllabus designers and textbook writers - toward the pivotal role individual differences, in general, and personality factors such as extroversion/introversion, in particular, can play in the process of second language acquisition. Though the present study failed to provide evidence for the relatedness of such psychological factors in individuals and their writing skill, literature has more to offer regarding the correlation between these factors as well as many other aspects of learners' proficiency which are thought to be somehow influenced by their diverse personality traits. Thus, to further disambiguate the intricacies surrounding extroversion/introversion dichotomy, future investigators are recommended to launch more in-depth probes into the correlation between these personality traits and other less-attended aspects of language acquisition, including more minute aspects of learners' written and oral 
performance.

\section{References}

Alarcon, J. B., \& Morales, K. N. S. (2011). Grammatical cohesion in students' argumentative essay. Journal of English and Literature, 2(5), 114-127.

Alavinia, P., \& Sameei, A. (2012). Potential bonds between extroversion/introversion and Iranian EFL learners' listening comprehension ability. English Language Teaching, 5(5), 19-30. http://dx.doi.org/10.5539/elt.v5n5p19

Arnold, J., \& Brown, H. D. (1999). A map of the terrain. In J. Arnold (Ed.), Affect in language learning (pp. 1-24). Cambridge: Cambridge University Press.

Brown, H. D. (1994). Principles of language learning and teaching (3rd ed.). Englewood Cliffs, NJ: Prentice Hall Regents.

Celce-Murcia, M. (2001). Language skills: Writing. In M. Celce-Murcia (Ed.), Teaching English as a second or foreign language (3rd ed., p. 205). Boston, MA: Heinle \& Heinle.

Dastjerdi, H. V., \& Hayati, S. S. (2011). Quality of Iranian EFL learners' argumentative essays: Cohesive devices in focus. Mediterranean Journal of Social Sciences, 2(2), 65-76.

Dhody, A. (2012). A comparative study of introversion and extroversion of adolscence girls of high and low socio economic status. Awadh International Journal of Information Technology and Education, 1(1), 76-81.

Ellis, R. (2008). The study of second language acquisition. Oxford: Oxford University Press.

Fazeli, S. H. (2012). The relationship between the extraversion trait and use of the English language learning strategies. Indian Journal of Science and Technology, 5(4), 2651-2657.

Krapels, A. R. (1990). An overview of second language writing research. In B. Kroll (Ed.), Second language writing: Research insights for the classroom (pp. 37-56). Cambridge: Cambridge University Press. http://dx.doi.org/10.1017/CBO9781139524551.007

Kroll, B. (1990). Introduction. In B. Kroll (Ed.), Second language writing: Research insights for the classroom (pp. 1-5). Cambridge: Cambridge University Press. http://dx.doi.org/10.1017/CBO9781139524551.003

Lightbown, P. M., \& Spada, N. (2006). How languages are learned (3rd ed.). Oxford: Oxford University Press.

Skehan, P. (1989). Individual differences in second language learning. London: Edward Arnold.

Verduyn, P., \& Brans, K. (2012). The relationship between extraversion, neuroticism and aspects of trait affect. Personality and Individual Differences, 52, 664-669. http://dx.doi.org/10.1016/j.paid.2011.12.017

Wakamoto, N. (2000). Language learning strategy and personality variables: Focusing on extroversion and $\begin{array}{lllll}\text { introversion. International Review of Applied Linguistics, } 38, & 71-81 .\end{array}$ http://dx.doi.org/10.1515/iral.2000.38.1.71

Widyastuti, O. (2012). A correlational study between extroversion, vocabulary mastery, and writing ability of the tenth grade students of SMA Negeri 4 Surakarta in the academic year of 2011/2012 (Unpublished thesis, Surakarta: Teacher Training and Education Faculty, Sebelas Maret University).

Zafar, S., \& Meenakshi, K. (2012). A study on the relationship between extroversion-introversion and risk-taking in the context of second language acquisition. International Journal of Research Studies in Language Learning, 1(1), 33-40. http://dx.doi.org/10.5861/ijrs1l.2012.v1i1.42

\section{Copyrights}

Copyright for this article is retained by the author(s), with first publication rights granted to the journal.

This is an open-access article distributed under the terms and conditions of the Creative Commons Attribution license (http://creativecommons.org/licenses/by/3.0/). 